\title{
Catecholaminergic Polymorphic Ventricular Tachycardia Type 2
}

National Cancer Institute

\section{Source}

National Cancer Institute. Catecholaminergic Polymorphic Ventricular Tachycardia Type

2. NCI Thesaurus. Code C148368.

An autosomal recessive condition caused by mutation(s) in the CASQ2 gene, encoding calsequestrin-2. It is characterized by a relative resting bradycardia and a slight prolong ation of the QT c interval. Polymorphic ventricular tachycardia may be induced with exercise stress testing or isoproterenol infusion. 